\begin{tabular}{|c|c|c|}
\hline $\begin{array}{l}\text { PKS } \\
\text { PUBLIC } \\
\text { KNOWEDGE } \\
\text { PROJECT }\end{array}$ & $\begin{array}{c}\text { REVISTA DE GEOGRAFIA } \\
\text { (RECIFE) } \\
\text { http://www.revista.ufpe.br/revistageografia }\end{array}$ & $\begin{array}{l}\text { OJS } \\
\frac{\text { OPEN }}{\text { OPUNAL }} \\
\text { SYSTEMS }\end{array}$ \\
\hline
\end{tabular}

\title{
O PODER DE NOMEAR E O INTERESSE POLÍTICO EM RENOMEAR: CONFLITOS TOPONÍMICOS EM NILÓPOLIS- RJ
}

\author{
Enderson Abuquerque ${ }^{1}$, Miguel Angelo Ribeiro ${ }^{2}$ \\ ${ }^{1}$ Doutorando pelo Programa de Pós-Graduação em Geografia da UERJ. E-mail: \\ endersonalbuquerque@yahoo.com.br \\ ${ }^{2}$ Professor associado do Instituto de Geografia da UERJ.E-mail: mamikisi@gmail.com
}

Artigo recebido em 10/06/2017e aceito em 15/04/2018

\begin{abstract}
RESUMO
O presente artigo tem por objetivo discutir o uso político-partidário das toponímias no município fluminense de Nilópolis. A cidade em questão, componente da Região Metropolitana do Rio de Janeiro e conhecida na escala nacional e internacional por sediar a Escola de Samba Beija Flor de Nilópolis, presencia um intenso processo de modificações de nomes de equipamentos públicos pautados por interferências políticas. Como a etimologia sugere, toponímia diz respeito ao estudo dos nomes dos lugares, contudo, para a análise em questão, selecionamos apenas os espaços públicos que sofreram alteração de nomenclatura recentemente como forma de expressar o poder deum determinado segmento político, demarcando um território. A análise dessa questão no cenário nilopolitano aponta para a predominância de dois grupos políticos os quais influenciam fortemente na decisão de nomear tais espaços: o clã Abraão-Sessim e os Calazans, os quais demarcam no espaço um poder territorial.
\end{abstract}

Palavras-chave: Nilópolis; Grupos políticos; Poder; Toponímia.

\section{THE POWER TO NAME AND THE POLITICAL INTEREST IN RENAME: TOPONIMMIC CONFLICTS IN NILÓPOLIS-RJ}

\begin{abstract}
This article aims to discuss the political-partisan use of toponyms in the Rio de Janeiro municipality of Nilópolis. The city in question, part of the Metropolitan Region of Rio de Janeiro and known nationally and internationally for hosting the Beija Flor de Nilópolis Samba School, witnessed an intense process of modifications of names of public equipment ruled by political interference. As the etymology suggests, toponymy refers to the study of place names, however, for the analysis in question we select only those public spaces that have recently undergone a change of nomenclature as a way of expressing the power of a given political segment, demarcating a territory. The analysis of this issue in the nilopolitan scenario points to the predominance of two political groups, which strongly influence the decision to name such spaces: the Abraão-Sessim clan and the Calazans, who demarcate a territorial power in space.
\end{abstract}

Keywords: Nilópolis; Political groups; Power; Toponymy. 


\section{INTRODUÇÃO}

Este artigo tem por objetivo analisar as manifestações de poder no município de Nilópolis contemplando a análise das suas toponímias. O recorte temporal utilizado para essa análise abrange o período compreendido entre os anos de 1947 - ano da instalação do município - até o período atual no qual se verifica uma tensão entre os grupos políticos locais no sentido de renomear espaços públicos. Embora as produções acadêmicas referentes à discussão toponímica sejamabundantes no âmbito geográfico, ainda não existem trabalhos que contemplem aessa temática na escala aqui proposta.

Quanto à operacionalização referente à metodologia da pesquisa, recorremos a obras acadêmicas que trataram da discussão a respeito das categorias poder, toponímia e território. O caminho de investigação escolhidovisa analisar como ocorre a correlação de forçasno espaço nilopolitano a partir do poder de nomear e o interesse político em renomear espaços públicos. Utilizamos, também, fotografias como forma de expressar visualmente a os territórios políticos. No intuito de responder a esse questionamento, o artigo se divide em três partes. Na primeira ambicionamos contextualizar nosso recorte espacial no bojo da Baixada Fluminense e da Região Metropolitana do Rio de Janeiro (RMRJ) a partir da sua inserção socioeconômica. A segunda parte analisará a dimensão política do município em tela enquanto a terceira parte discutirá o processo toponímico e sua dimensão política. Afim de apontar esse processo no contexto municipal, analisaremos alguns equipamentos públicos que tiveram seus nomes alterados para atender aos interesses políticos vigentes em determinado período, tais como os postos de saúde, as praças e estabelecimentos educacionais.

\section{NILÓPOLIS NO CONTEXTO DA REGIÃO METROPOLITANA DO RIO DE JANEIRO}

Nilópolis, nosso recorte espacial, localiza-se na Região Metropolitana do Rio de Janeiro e, juntamente com os municípios de Nova Iguaçu, Duque de Caxias, São João de Meriti, Belford Roxo, Mesquita, Japeri, Queimados, Magé, Guapimirim, Itaguaí, Paracambi e Seropédica, compõe a Baixada Fluminense, conforme registra a Figura 1. Embora ocupe oficialmente uma área de $19.157 \mathrm{~km}^{2}$, segundo o IBGE, mais de $10 \mathrm{~km}^{2}$ de sua área pertenceao Campo de Instrução Militar do Gericinó (Exército do Brasil) e apenas $9 \mathrm{~km}^{2}$ são ocupados por sua população de 157.425 residentes de acordo com o Censo Demográfico de 2010. Essa configuração territorial confere ao município densidade demográfica superior a 
8.000 hab. $/ \mathrm{km}^{2}$, uma das maiores do país, materializando um processo de conurbação com bairros da cidade do Rio de Janeiro e com os municípios limítrofes.

Figura 1: Localização do município de Nilópolis na RMRJ e na Baixada Fluminense

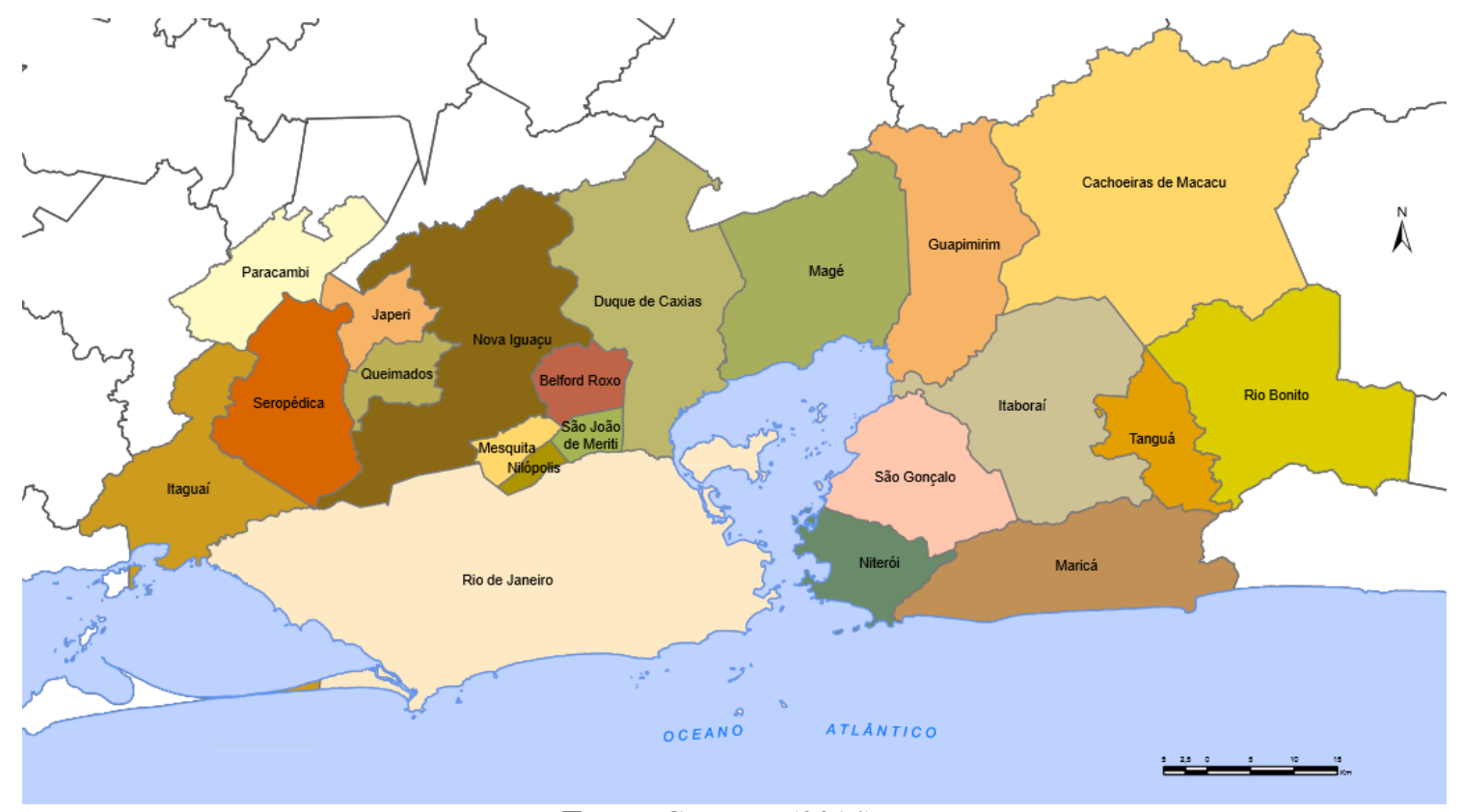

Fonte: CEPERJ (2014)

Sobre as intervenções realizadas pelo governo de Nilo Peçanha entre os anos de 1909 e 1910, Lago (2000, p. 67) assinala que as

obras de saneamento e drenagem executadas na Baixada Fluminense nesse período, em vez de impulsionar a produção agrícola para o abastecimento da cidade, abriram novas fronteiras para a expansão imobiliária. Surgia nesse momento um novo padrão de produção do espaço construído urbano, os chamados "loteamentos periféricos", que mudaria, doravante, a forma e o conteúdo não apenas do Rio de Janeiro, mas das demais grandes cidades brasileiras.

A alteração da forma e conteúdo aludida por Lago se manifestou através do adensamento demográfico dos municípios vizinhos ao Rio de Janeiro. Por consequência, houve a expansão da mancha urbana, até então limitada à cidade do Rio de Janeiro. No contexto fluminense tal processo se materializou juridicamente com a criação da Região Metropolitana do Rio de Janeiro em 1973. Essa RM foi criada com 17 municípios, dentre eles Nilópolis e, tendo como seu núcleo o então município da Guanabara, atualmente constituindo o município do Rio de Janeiro e sediando a capital do Estado do Rio de Janeiro desde 1975, quando da fusão imposta pelo governo federal.

O último Censo demográfico do IBGE (2010) registra o caráter altamente concentrador do ponto de vista populacional do núcleo da RMRJ quando comparado aos demais municípios. Essa área concentra $74,1 \%$ da população residente no estado, perfazendo um total populacional de 11.823.752 habitantes. Entretanto, 6.323 .037 desses indivíduos 
residem no município do Rio de Janeiro. Dessa forma, o núcleo da RMRJ abriga população superior à soma dos outros 20 municípios que a compõem atualmente, ratificando a forte concentração populacional metropolitana.

Nesse contexto, o município nilopolitano se inscreve como integrante de sua periferia (RIBEIRO \& O’NEILL, 2012), a Baixada Fluminense.Nilópolis apresenta índices econômicos pífios quando comparado aos de outros municípios da Baixada Fluminense e da Região Metropolitana. As receitas tributárias dos municípios da Região Metropolitana, em 2007, por exemplo, foram de R 208.713 .877 (em mil reais). O município nilopolitano, nesse mesmo ano, contribui para a RMRJ com uma arrecadação tributária de R\$ 1.198.642, correspondendo a apenas $0,57 \%$ do PIB total dessa região (IBGE, 2007). Para o ano de 2012 o PIB total da Região Metropolitana, na qual Nilópolis está inserida, foi de R\$261. 090. 608 (em mil reais). O município nilopolitano contribui com apenas $0,74 \%$ desse valor, com um PIB de R\$ 1.935.707.

O espaço nilopolitano, conforme exposto, apresenta pouca expressividade quanto ao desenvolvimento econômico e, consequentemente, é altamente dependente dos repasses federais para sua gestão. Por sua vez, a gestão municipal utiliza do poder para nomear espaços públicos como forma de demarcar o domínio territorial de seu grupo, pois o território se configura a partir de relação de poder, a qual controla o espaço do ponto de vista material e simbólico. Nesse sentido, se por um lado nomear os espaços públicos simboliza a territorialização desse local, por outro é um indicativo do grau de poder do grupo beneficiado.

Dessa feita, enquanto a primeira parte deste artigo se propôs a situar Nilópolis no contexto econômico da RMRJ, a segunda ambiciona um debate relativo ao exercício do poder considerando as principais forças políticas do município no período atual e sua capacidade política em nomear espaços públicos.

\section{O PODER SEM PUDOR: ATUAÇÃO DOS GRUPOS POLÍTICOS NO ESPAÇO NILOPOLITANO}

Nomear espaços públicos ao mesmo tempo em que sugere a legitimidade do homenageado, expõe a força política daquele que homenageia. Por outro lado, grifar os espaços públicos em benefício político de um determinado grupo suscita uma discussão referente à necessária separação entre os interesses públicos e privados dos gestores municipais. Nesse sentido, discutir o sentido das toponímias para o caso em questão enseja considerar a noção de poder e do território - o qual consiste em sua manifestação espacial - e a 
relação entre as esferas pública e privada. Com efeito, esta parte do artigo iniciará com um debate teórico relativo ao poder e seu exercício no contexto nilopolitano e, posteriormente, a partir da distinção entre público e privado, discutiremos as apropriações simbólicas dos espaços públicos municipais por meio das toponímias.

O topônimo, objeto de estudo da toponímia, diz respeito ao nome dos lugares. Nomear os lugares, por sua vez, cumpre uma dupla função conforme sustenta Claval (2001, p. 189) ao afirmar que "o batismo do espaço e de todos ospontos importantes não é feito somente para ajudar unsaos outros a se referenciar. Trata-se de uma verdadeiratomada de posse (simbólica ou real) do espaço". Desse modo, além do referencial espacial, batizar os lugares serve, em alguma medida, como uma manifestação de poder daquele que o nomeia ou da parte de quem impõe a homenagem.

O poder ao se efetivar sobre um espaço cria uma demanda de reflexão geográfica, pois faz emergir um território. O território, simbólico ou funcional, é "um espaço definido e delimitado por e a partir de relações de poder”, conforme aponta Souza (2010, p. 78). Afinado a essa preposição, a discussão do território suscita, indubitavelmente, o debate referente às relações de poder e, por extensão, aos grupos de poder atuantes em um determinado espaço e aos sujeitos imbricados. Convém acrescentar que o poder é sempre relacional devido a sua natureza de ser propriedade de um grupo como defende Arendt (2016), estar presente em todos os espaços, conforme expõe Foucault (2016) e por isso se inseri em todas as relações, como esmiúça Raffestin (1993). Deste modo, o poder precisa de uma legitimação social tecida por indivíduos e, sobretudo, por instituições. As eleições legitimam e reforçam, em alguma medida, o poder. Com efeito, no contexto nilopolitano atual, dois grupos respondem pelo exercício desse poder político-eleitoral: o clã Abraão-Sessim e os Calazans.

Seguindo essa linha de raciocínio a partir dos grupos políticos atuantes no referido município, podemos afirmar que acronologia dos territórios políticos nilopolitanos aponta para existência de movimentos distintos no tocante as hegemonias dessa forças políticas. Essas distinções temporais, por sua vez, nos permitem dividir o processo de construção dessas territorialidades em dois períodos. O primeiro se inicia a partir de sua emancipação em 1947 e se estende até o início da década de 1970, o qual aponta para a fragmentação e para a alternância de nomes no poder executivo municipal. O segundo período é caracterizado pelo surgimento e posterior consolidação do grupo hegemônico na política local, o clã AbraãoSessim. 
Descendentes de sírio-libaneses, os membros dessa família chegaram ao município na década de 1930. Aos poucos a família foi se enriquecendo e, ao contrário dos imigrantes judeus que ao se capitalizarem deixaram a cidade, os sírio-libaneses se mantiveram e passaram a atuar na política local (SIMÕES, 2008). Com a emancipação de Nilópolis em 1947, então $4^{\circ}$ Distrito de Nova Iguaçu, esse grupo, que atuava como suporte político de Getúlio de Mourapassou a comandar e gerenciar o referido Distrito elevado a categoria de município (ALVES, 2003).

Com o Golpe Militar de 1964 os integrantes da família Abraão-Sessim filiaram- se a Aliança Renovadora Nacional (ARENA), partido de apoio político ao regime militar. Devido à proximidade com o governo, a família se beneficiou das intervenções na estrutura política da Baixada Fluminense. Em fevereiro de 1970 o prefeito de Nilópolis, João Cardoso, eleito para o cargo pela terceira vez, foi cassado sob suspeita de boicotar o regime vigente. Seu delator e primeiro secretário da Câmara Municipal era Miguel Abraão. Aniz Abraão (popularmente conhecido como Anísio) ocupava o cargo de vereador. "A partir desse momento teve início a conjunção entre poder militar, poder familiar e contravenção em Nilópolis" (ALVES, 2003, p.104). Tal conjuntura refletiu na agremiação carnavalesca gerida por Anísio Abraão, a Beija-Flor de Nilópolis. Na condição de presidente, e dessa forma exercendo poder sobre a escolha dos enredos, nos de 1973, 1974 e 1975 a escola de samba de Nilópolis apresentou enredos enaltecendo o regime militar e suas realizações.

Os membros com atuação política desse grupo são Anísio Abraão, Miguel Abraão, Farid Abraão, Nelson Abraão, Jorge David, Abraãozinho, Nelsinho Abraão, Ricardo Abraão, Sérgio Sessim e Simão Sessim. O predomínio desse grupo político no contexto nilopolitano é explicado em parte pela gerencia da Beija-Flor. A cronologia das gestões municipal e da agremiação indica parte dessa estrutura. Em 1972 Nelson Abraão foi o primeiro membro do clã a assumir a Escola de Samba sem ser interino - depois dele apenas um presidente eleito não tinha Abraão como sobrenome. Em 1973 Simão Sessim tornou-se o primeiro do clã a assumir a prefeitura de Nilópolis- depois dele apenas dois prefeitos eleitos não pertenciam ao grupo ou não haviam sido lançados politicamente por eles.

Embora seja verdade que um membro do clã já era prefeito de Nilópolis em 1973, a projeção alcançada pela Beija-Flor na escala nacional permitiu a esse grupo um espaço de exposição de seus feitos gerenciais não possível a nenhum outro adversário político da cidade. A partir desse processo, o grupo passou a usar o prestígio da instituição para uso político 
eleitoral próprio, vinculando o nome dos membros do clã aos projetos sociais realizados pela instituição carnavalesca.

Convém ainda salientar a proeza do clã Abraão-Sessim nos legislativos municipal, estadual e federal. Desde o ano de 1972 o clã mantém ao menos um representante direto na Câmara Municipal de Nilópolis. Na esfera estadual os sírio-libaneses em questão só não tiveram representantes na legislatura de 2007-2010. Desde 1978, Simão Sessim representa o grupo na Câmara Federal sendo um dos deputados mais antigos da referida Casa com dez mandatos consecutivos.

Nas eleições municipais de 2012 a oposição se uniu em torno da candidatura de Alessandro Calazans. Apesar dessa união e do baixo índice de aprovação do mandato de Sérgio Sessim que tentava a reeleição, Calazans venceu o pleito por uma diferença de apenas $1,85 \%$ dos votos válidos e tornou-se o segundo prefeito eleito da cidade não vinculado ao clã Abraão-Sessim desde que estes assumiram a prefeitura nilopolitana, conforme aponta o Quadro 1. Nessa condição, antes dele, só havia João Batista da Silva (1977-1981).

Quadro 1- Prefeitos de Nilópolis - 1973-2020

\begin{tabular}{|l|c|c|}
\hline \multicolumn{1}{|c|}{ Nome } & Período & Condição \\
\hline Simão Sessim* & 1973 a 1977 & Eleito \\
\hline João Batista da Silva & 1977 a 1981 & Eleito \\
\hline Zélio Sabino Barbosa & 1981 a 1982 & Vice Interino \\
\hline Miguel Abraão * & 1983 a 1988 & Eleito \\
\hline Jorge David * & 1988 a 1992 & Eleito \\
\hline Manoel da Silva Rosa ** & 1992 a 1996 & Eleito \\
\hline José Carlos Cunha** & 1996 a 2000 & Eleito \\
\hline Farid Abraão * & 2001 a 2008 & Eleito \\
\hline Sérgio Sessim* & 2009 a 2012 & Eleito \\
\hline Osvaldo Costa ** & 2012 & Vice Interino \\
\hline Alessandro Calazans & 2013 a 2016 & Eleito \\
\hline Farid Abraão * & 2017 a 2020 & Eleito \\
\hline$*$ Familiares do clã Abraão-Sessim ** Iniciaram-se na política por intermédio do clã. \\
\hline
\end{tabular}

Fonte: organizado pelos autores, 2017.

Como exposto no quadro 1, Alessandro Calazans rompeu a hegemonia do grupo libanês nas eleições municipais de 2012. Antes de assumir a prefeituraem 2013, Calazans foi vereador na cidade uma vez e deputado estadual em três mandatos consecutivos a partir das eleições de 1998. Além de Alessandro Calazans, seu irmão, Vander Calazans também foi vereador no mandato de 2008 a 2012. A família Calazans atua na cidade no ramo imobiliário e o pai de ambos, Alcebíades Calazans, preside uma instituição social na cidade.

Os Abraão-Sessim e os Calazans se destacam ao utilizarem o espaço público de maneira privativa ao impor o nome de seus pares a esses espaços, nomeando equipamentos 
públicos como uma forma de manifestação de poder, marcando territórios a partir do uso político mesclando, assim, as esferas pública e privada. Tal discussão será tratada na próxima parte deste artigo.

\section{APROPRIAÇÕES SIMBÓLICAS DOS ESPAÇOS PÚBLICOS: TERRITORIALIZAÇÕES POR MEIO DE TOPONÍMIAS EM NILÓPOLIS}

A discussão referente à delimitação do que seria espaço público pode ser feita a partir de dois níveis de análise não excludentes. O primeiro diz respeito à gestão desses espaços públicos e o segundo ao seu acesso. Dessa forma, Gomes (2002) nos lembra da existência de espaços públicos quanto sua gestão, porém de acesso restrito como hospitais e áreas militares e de espaços privados no tocante à gestão, porém de acesso público como os shopping centers. Nesse sentido, as limitações impostas pela forma de gestão ou pelo acesso ao espaço tornam-se insuficientes para classificá-lo como público ou privado. Entretanto, os espaços apropriados simbolicamente por meio de toponímias em Nilópolis, foco desta análise, se caracterizam por serem públicos tanto no acesso quanto na gestão.

Os cargos públicos, por sua vez, são em larga medida ocupados por indivíduos que priorizam projetos políticos pessoais e do grupo político ao qual pertencem. Tais grupos lançam mão de estratégias que atendam a esses intuitos e lhes permitam apropriar-se da máquina pública pelo maior tempo possível. Contudo, para Gomes (2002, p. 184),

\section{hoje no Brasil, a ideia de coisa pública se confunde, em grande medida, com algo de baixa qualidade ou de uso exclusivo das camadas populares, como no caso de hospitais, escolas, parques, centros de lazer etc. De certa forma, a mesma desvalorização ocorre com o espaço público, uma vez que o acesso é livre, e a frequência majoritária é composta, em geral, de elementos oriundos dessas camadas populares.}

Gomes alude a respeito de duas características relativas aos serviços públicos, sua baixa qualidade e o fato deles serem usados por pessoas das camadas populares. Devido à segunda característica e, em que pese a pouca qualidade desses serviços, ainda assim sua apropriação é importante do ponto de vista político. O fato de esses serviços serem usados em sua maioria por pessoas pobres possibilita a alguns gruposse beneficiarem politicamente com os votos dessa camada mais numerosa da população que utiliza o serviço, exercendo um poder sobre os mesmos. Assim, há um esforço em grifar os espaços públicos populares com o nome de algum membro do clã político, constituindo-se, desse modo, em uma apropriação subjetiva do referido espaçopor meio de toponímias. Em nosso recorte espacial, o principal grupo político da cidade, os Abraão-Sessim, batizaram cinco equipamentos públicos com seu sobrenome: dois postos de saúde, uma praça e duas escolas municipais. Espaços justamente 
caracterizados pela baixa qualidade dos serviços prestados às camadas mais populares, conforme Gomes assevera.

Nomear espaços públicos com nomes de membros políticos serve para ratificar para "os de fora” a força local de determinado grupo. Assim, quanto mais equipamentos públicos tiverem seu nome, maior será a manifestação de poder emanada pelo respectivo grupo, uma vez que "o espaço é, sob essa dinâmica, sempre objeto de conflitos, pois estabelecer um território de domínio de um grupo significa a afirmação de sua diferença em oposição aos demais" (GOMES, 2002, p. 181).

Localizado até então na Avenida Getúlio Vargas, principal via de acesso a cidade do Rio de Janeiro e área central de Nilópolis, o maior posto de saúde do município em tamanho físico, número de funcionários e especialidades, recebeu o nome de Jorge David em homenagem ao ex-prefeito e membro do clã libanês. No último ano da gestão municipal do prefeito Calazans (2016), o espaço que abrigava o posto de Saúde foi vendido à iniciativa privada. Os serviços médicos prestados por esse posto foram transferidos para uma unidade nova batizada de Melchiades Calazans Filho (figura 2). Desse modo, não obstanteretirar o nome do grupo político rival de uma área de grande circulação de pessoas na cidade, Alessandro Calazans rebatizou o posto de saúde com o nome de seu familiar.

Figura 2 - Foto do principal posto de saúde municipal batizado de Jorge David e rebatizado para Melchiades Calazans Filho após seu deslocamento da área central da cidade.
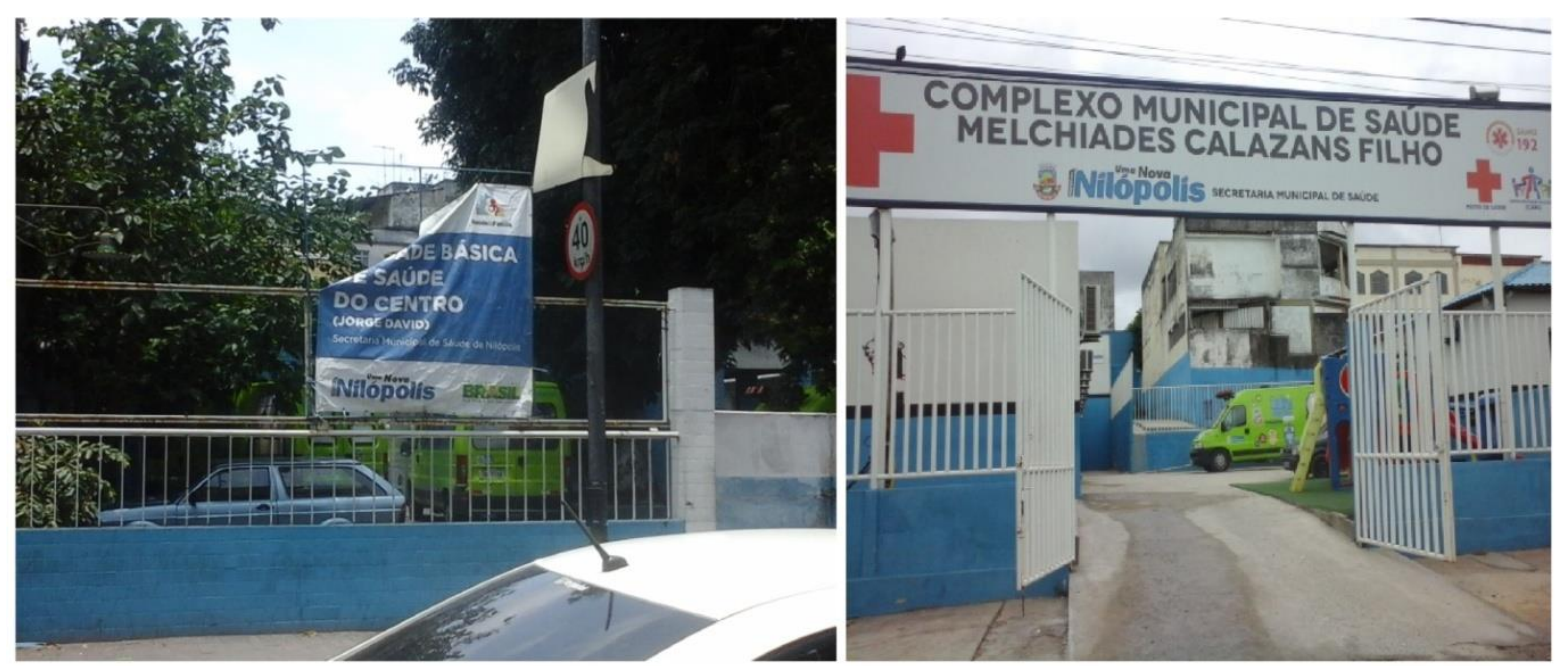

Fonte: Acervo Enderson Albuquerque, 2017.

Os Abraão-Sessim selecionaram também a principal praça pública da cidade para homenagear outro membro de seu grupo. Este fixo localiza-se no centro de Nilópolis, do lado direito da estação de trem daqueles que chegam da cidade do Rio de Janeiro. Por efeito de sua 
localização, os usuários desse meio de transporte residentes em alguns bairros mais afastados passam, necessariamente, por essa praça. Além disso, a mesma é ponto terminal de ônibus e motos-táxi que conectam o centro à periferia de Nilópolis e aos municípios vizinhos de Mesquita e São João de Meriti.

Essa praça, Paulo de Frontin, foi renomeada para Miguel Abraão. A alteração ocorreu durante a primeira gestão do prefeito Farid Abraão e, tendo como representante na Câmara Municipal, o vereador Abraãonzinho. Os políticos citados são respectivamente irmão e filho do homenageado. Historicamente a praça representa o marco inicial da urbanização do município. Peres (2011, p. 3) relata que o busto de Paulo de Frontin "foi inaugurado em 08/05/1914, no mesmo dia da inauguração da parada de Trem Engenheiro Neiva", fixo importante para o processo de urbanização de Nilópolis. A homenagem em Nilópolis a Paulo de Frontin se deveu ao fato dele ter sido "responsável pela construção da primeira estação ferroviária do então povoado de São Matheus, inaugurada em 1914, pela construção das pontes ligando Nilópolis ao então Distrito Federal em 1919" (AZEVEDO e MONTEIRO, 2012, p. 83).

Apesar da oficialidade da troca do nome da referida praça, a gestão Calazans confeccionou placas com o nome anterior do logradouro como uma forma de não reforçar os interesses políticos do grupo rival, conforme exposto na figura 3. Na mesma placa ainda está indicada a logo da gestão Calazans: Uma Nova Nilópolis.

Figura 3 - Praça Central de Nilópolis com placa indicativa do nome anterior alusivo a Paulo de Frontin. 


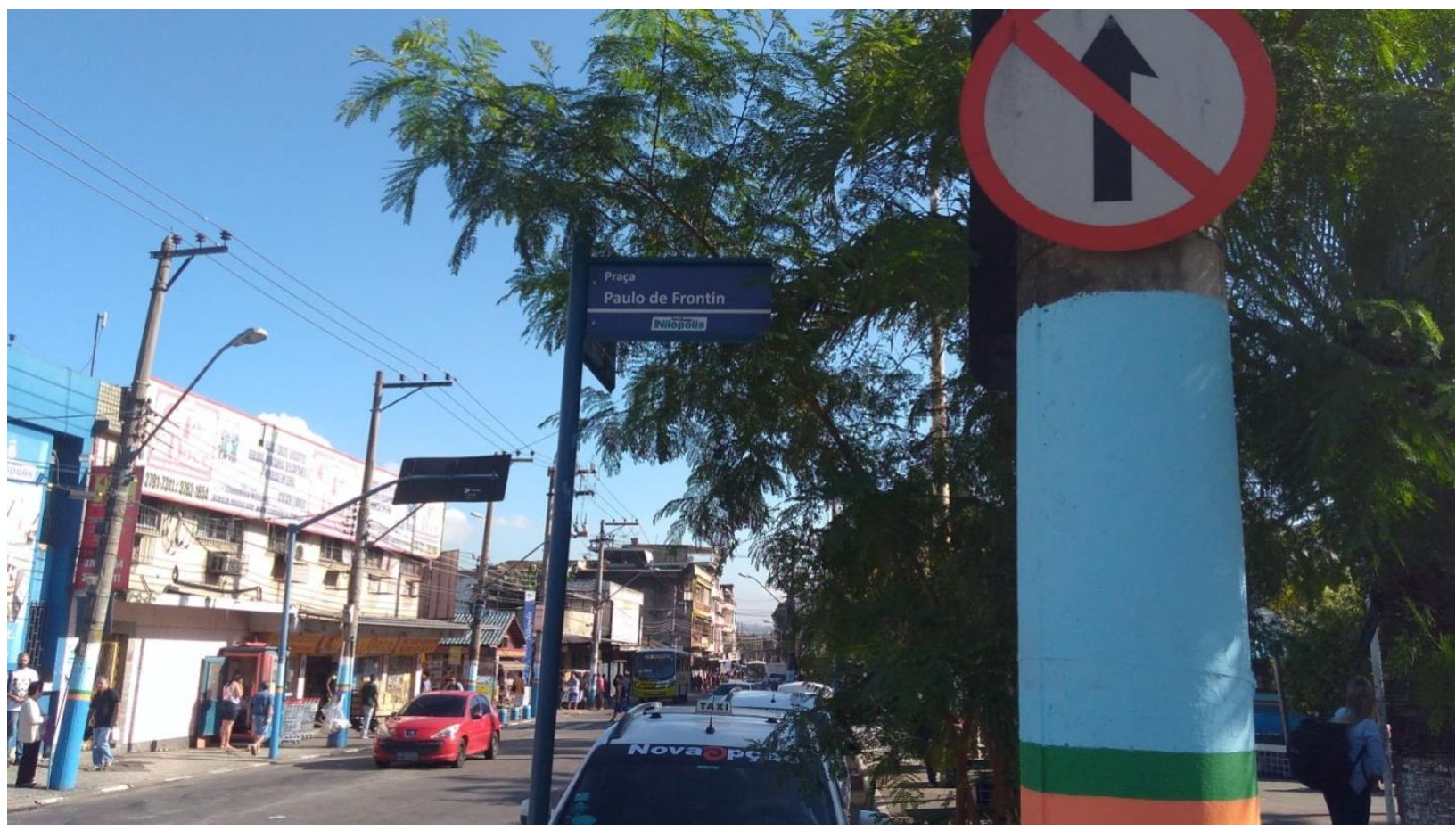

Fonte: Acervo Enderson Albuquerque, 2017

O esforço em aferir ganho político com a mudança do nome da praça ocorrida em 2007 não prosperou. Ainda hoje a homenagem ao membro do clã libanês não foi assimilada pela maior parte da população nilopolitana que desconhece a alteração da nomenclatura da referida praça. Mesmo em site de buscas na internet, o fixo em questão aparece com o nome anterior de Praça Paulo de Frontin. Entretanto, a mesma é reconhecida entre os moradores não pelo nome de um dos expoentes políticos do processo de formação da cidade, tampouco pelo nome do ex-prefeito, mas simplesmente pelo nome de "Praça do Chafariz" após a obra que a dotou de tal equipamento em 2001. Essa postura exemplifica a rejeição de parte da população frente à imposição das toponímias oficiais, pois, conforme argumenta Mello (2007, p. 9),

as toponímias oficiais são, evidentemente, reconhecidas pela população de um modo geral. Mas, as pessoas, igualmente contestam o aparelho de Estado no que tange às toponímias oficiais com sentimento, criatividade, entendimento e uma linguagem que transforma à sua maneira e perdura no tempo. As camadas populares cultivam símbolos que lhes são transmitidos, mas elegem ou propalam a memória simbólica dos lugares.

Por tais mecanismos, a praça passa a servir de exemplo para expor as mudanças políticas ocorridas em Nilópolis. Ademais, a escolha desses equipamentos não ocorre por acaso. Ao selecionarem o posto de saúde e a praça central do município, o clã libanês se beneficia sobremaneira da visibilidade procedente da privilegiada localização geográfica desses equipamentos para os moradores nilopolitanos. Este fixo pode ser tomado como o marco zero da cidade de Nilópolis, conforme já mencionado. A inauguração da parada de trem em 1914 contribuiu decisivamente para a aceleração do processo de urbanização de 
Nilópolis e de sua integração a malha urbana da cidade do Rio de Janeiro (ABREU, 2010). As áreas próximas à linha férrea tiveram imediata valorização fundiária culminando em sua rápida comercialização e em seu entorno surgiram às primeiras casas comerciais e a feira livre da cidade (NOGUEIRA, 2009). A parada de trem gestou, assim, o centro comercial e financeiro da cidade, exercendo papel importante de centralidade, originando fluxos de pessoas em busca de serviços ofertados.

Em razão da proximidade com a parada de trem, nas imediações da Praça Paulo de Frontin se estabeleceram, em um primeiro momento, as principais atividades econômicas e sociais. Dessa maneira, em 21 de março de 1917, no número 42 da mesma foi inaugurada a primeira escola pública de Nilópolis (Figura 4). Cumpre mencionar que no referido ano o atual município de Nilópolis ainda era um subdistrito de pouca importância econômica pertencente à municipalidade de Nova Iguaçu de modo que a escola foi construída pelo Governo do Estado.

Figura 4- Primeira escola pública do município inaugurada em 1917

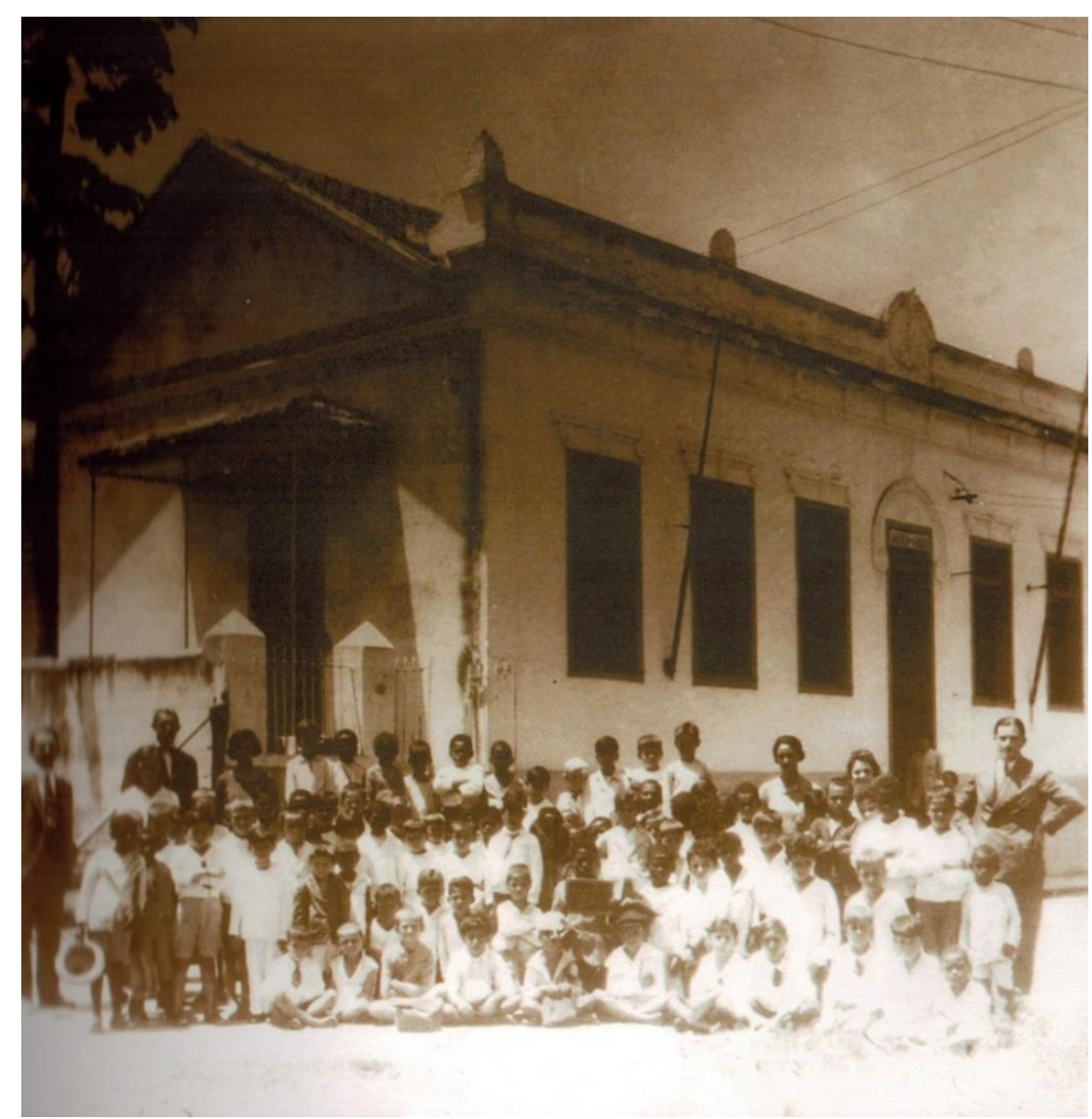

Fonte: Nogueira (2009, p.117) 
O prédio que sediou a escola foi construído entre os anos de 1914 e 1915 e "ainda conserva [va] em sua fachada o monograma do nome de João Alves Mirandella, seu primeiro proprietário"(AZEVEDO e MONTEIRO, 2012, p. 90). João Alves Mirandella adquiriu em 1900 a parte restante da fazenda São Matheus, juntamente com as suas edificações. Mais que um simples proprietário, Mirandella é de grande importância para a história nilopolitana. Sua relevância é de tal monta que um dos principais logradouros da Área Central nilopolitana tem por nome Avenida Mirandela, isso porque ele foi o responsável pela gênese da cidade de Nilópolis ao fazer o levantamento da planta da fazenda e lotear as terras. A divulgação da venda dos lotes foi realizada por meio de anúncios pagos em jornais de grande circulação como o Jornal do Comércio e o Jornal do Brasil. Em junho de 1914 “já haviam sido vendidos mais de 5.000 lotes e já em princípio de 1915 estava totalmente vendida a área loteada ao lado direito da estação, apenas aguardando as construções" (NILÓPOLIS, 2007, p.12).

Apesar da importância histórica atribuída ao prédio, a "força da grana que ergue e destrói coisas belas" foi mais forte que o apelo da edificação e assim, em julho de 2017, o que restava da fachada foi demolida para aconstrução de um prédio residencial, conforme atesta a figura 5 .

Figura 5 - Fachada remanescente da primeira escola da pública da cidade.

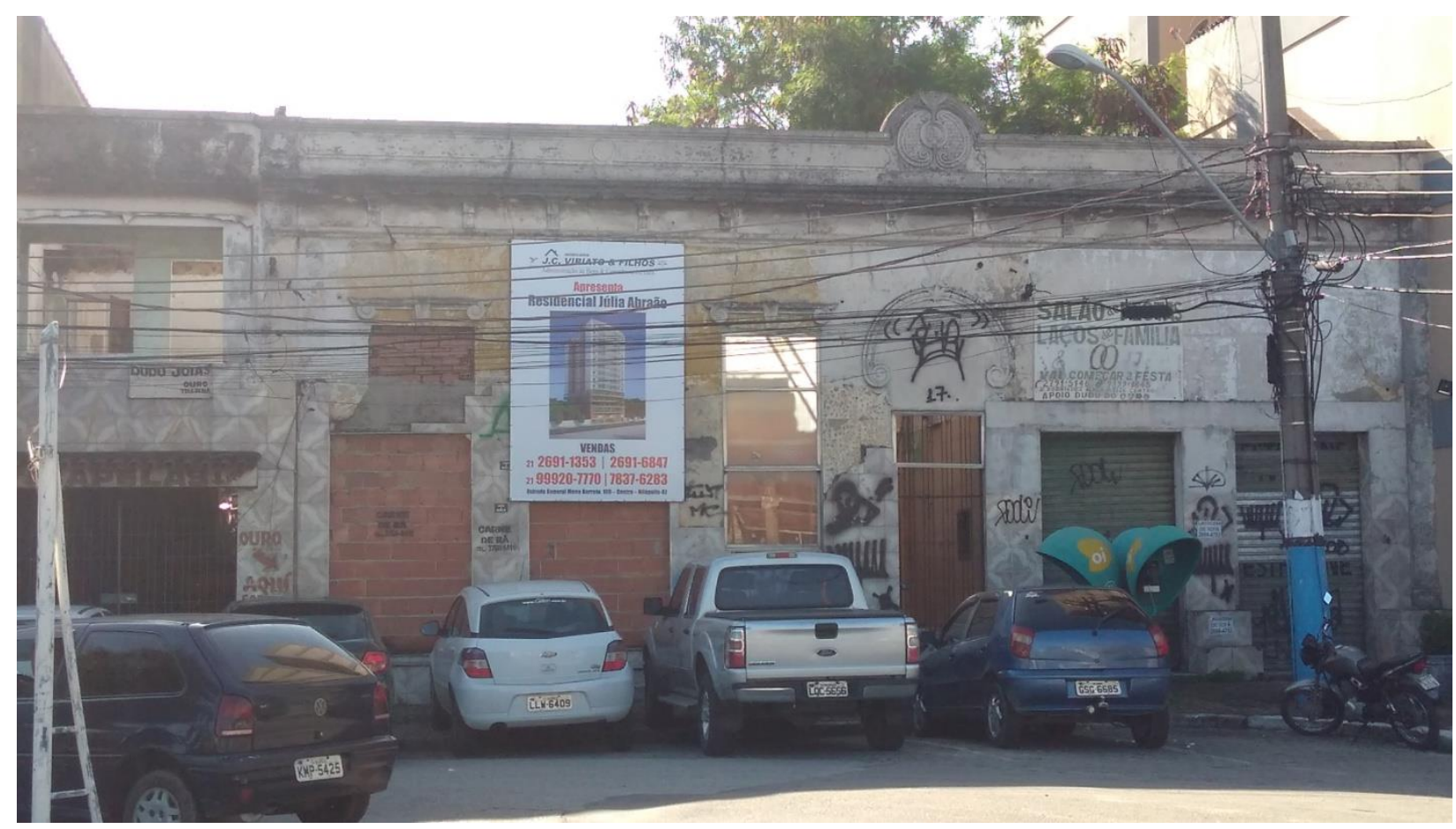

Fonte: Acervo Enderson Albuquerque, 2017 
$\mathrm{Na}$ parte superior da figura 5, podemos observar o estilo eclético que caracterizava a fachada da escola retratando o período no qual o prédio foi construído. Ao centro da foto, podemos observar um cartaz publicitário alusivo ao futuro residencial. Contudo, se por um lado essa mudança aponta para a refuncionalização do espaço sugerindo uma alteração da dinâmica econômica atual na cidade, por outro lado o tombamento da fachada histórica para a construção residencial indica, mais uma vez, uma explícita manifestação de poder por parte do clã Abraão-Sessim. Isso porque o futuro residencial se chamará Julia Abraão e ficará ao lado de outro fixo chamado Abraão David.

Ainda referentesà nomeaçãodas praças públicas, Jupiara e Otávio (2016, p. 61) apontam outro feito do grupo sírio-libanês para beneficiar a memória de pessoas ligadas ao clã ao revelar o exemplo de um agente de segurança que "depois de morto, [...] viraria nome de Praça em Nilópolis. Em 6 de outubro de 2006, inaugurou-se, pelas mãos do prefeito Farid Abraão David, irmão de Anísio, a praça Luiz Cláudio de Azeredo Vianna, 'renomado cidadão nilopolitano"'. O homenageado em questão fora torturador na época da ditadura militar e ao final do regime de exceção passou a trabalhar, também, para a contravenção, "atuando como lugar-tenente do bicheiro [Anísio], garantia salvo-conduto na construção da rede de influência e poder na região" (IBIDEM, p.55).

Quanto aos fixos educacionais, duas escolas foram nomeadas com o sobrenome libanês. A primeira homenagem foi a Regina Sessim, a qual batiza uma creche na área central do município. A homenageada é avó do ex-prefeito de Nilópolis, Sergio Sessim, e mãe do Deputado Federal Simão Sessim. Com a segunda homenagem de escola pública, o grupo foi mais audacioso, pois enquanto os demaisagraciados pertencentes ao clã eram pessoas já falecidas, em 2010 o contemplado foi um integrante vivo, Aniz Abraão David. 
Figura 6 - Escola municipal homenageando um membro Abraão e depois rebatizada na gestão Calazans
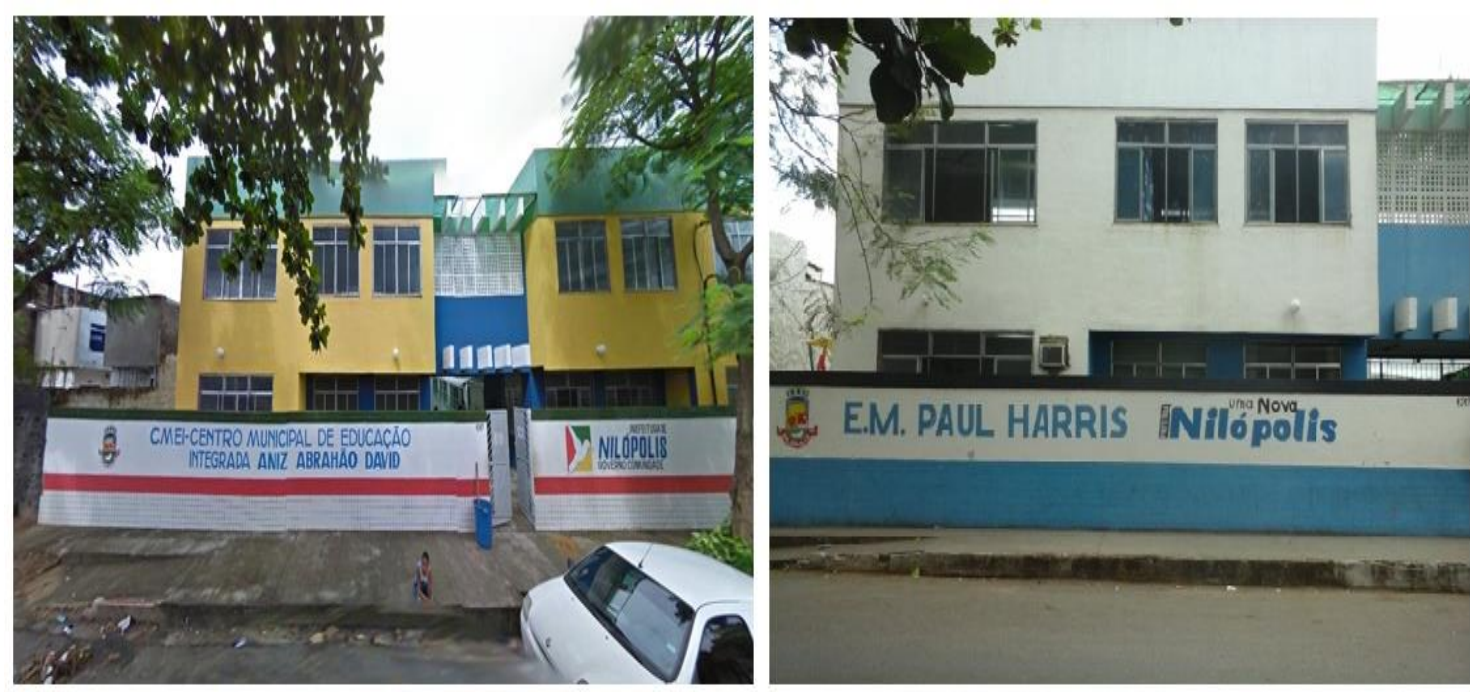

Fonte: GOOGLE STREET, 2010 Fonte: Acervo Enderson Albuquerque, 2017.

A figura 6 representa visualmente como a administração de Sergio Sessim (2008-2012) preocupou-se em imprimir a "marca política” dos Abraão-Sessim nos equipamentos públicos. O símbolo de seu mandato era um beija-flor, remetendo a instituição carnavalesca gerida pelo grupo.No entanto, em razão das mudanças políticas no cenário municipal, a escola foi rebatizada dois anos após sua inauguração para Paul Harris, conforme atesta a referida figura. Porém, como no mesmo espaço funciona ainda o Centro de Educação Integral (CEI), a identidade do grupo sírio-libanês não foi totalmente apagada desse espaço educacional. Esse CEI foi batizado com o nome de Nelson Abraão David.

A análise da figura 6 é emblemática, pois simboliza a disputa política pelo poder atualmente no município. A substituição do nome do membro do clã Abraão-Sessim e a troca da logomarca de um beija-flor para "Uma Nova Nilópolis", demonstram a tentativa da gestão Calazans paraenfraquecer o sobrenome do grupo rival. Entretanto, para alcançar esse intento, oprefeito se utiliza do mesmo expediente. Ainda no exemplo da escola em questão, embora aparentemente a troca do nome não remeta de forma direta aos membros de sua família, tal escolha não se deveu apenas a notabilidade do novo homenageado, considerou-se, também, uma estratégia política, o que reafirma a disputa de poder dos Calazans diante dos AbraãoSessim.

O estadunidense Paul Harris é fundador do Clube Rotary. Essa instituição, composta por empresários dedicados a práticas de caridade, é presidida atualmente no município por Alcebíades Calazans, pai de Alessandro Calazans, o qual já presidiu o Clube Rotary de 
Nilópolis por quatro vezes. Dessa forma, guardadas as devidas proporções, a instituição assistencialista está associada ao referido grupo político Calazans, do mesmo modo que a escola de samba Beija-Flor ao clã sírio-libanês.

Quando ainda era deputado estadual, Alessandro Calazans usou seu poder político na Assembleia Legislativa do Rio de Janeiro (ALERJ) para nomear o hospital de referência em partos e cirurgias de varizes, inaugurado em julho de 2006 em Nilópolis, com o nome de seu avô: hospital Vereador Melchiades Calazans. Essa unidade de saúde apresenta uma associação expressiva com o grupo político, de tal forma que as pessoas ao se referir ao centro de saúde, o nomeiam popularmente de "o hospital do Calazans". Alguns têm a clareza de ser a unidade de saúde fruto do empenho político do referido político, entretanto, há uma parcela menos esclarecida entre os moradores do município que julgam ser o hospital de propriedade do prefeito, como se fosse um centro de atendimento comunitário. Ao se tornar prefeito, Calazans homenageou ainda sua avó com o nome de uma creche. A creche Izaura Calazans inaugurada em agosto de 2013. Esta creche foi rebatizada para Rubens da Gama Menezes, exvereador do município ligado ao clã Abraão-Sessim, em 2018, durante a gestão de Farid Abraão.

Como já pontuado, a territorialização mesmo quando simbólica como ocorre com as toponímias, prejudica o caráter amplamente público dos lugares. Se o espaço serve como referencial identitário, essa referência é comprometida quando há a apropriação por um grupo. Grafar nos equipamentos públicos o sobrenome de pessoas ainda atuantes no sistema político local atende apenas aos simpatizantes desse grupo e serve como manifestação de poder para seus opositores. Ambos os casos, homenagear os pares ou afrontar os opositores, evidenciam o caráter estritamente político-partidário mesquinho pelo qual agem os governantes municipais atuais em Nilópolis.

Nas eleições municipais de 2016, Calazans foi derrotado nas urnas por Farid Abraão. O prefeito eleito afirmou em entrevista a um jornal fluminense que voltaria a pôr Beija-Flores nos principais acessos ao município, os quais haviam sido retirados por Calazans durante seu mandato em razão da analogia à agremiação presidida pelo grupo rival. As aves ainda não foram recolocadas, porém, a escola municipal que tinha o nome do patrono de honra da BeijaFlor e que na gestão de seu rival político havia sido alterada para o nome do fundador do grupo Rotary (figura 6), voltou a receber o nome do contraventor libanês, irmão do atual prefeito. 
Do mesmo modo que a escola municipal, o posto de saúde que passou a compor o complexo Melchiades Calazans Filho durante a gestão de Alessandro Calazans, voltou a ter o nome de Jorge da David na atual gestão municipal. O homenageado é irmão do atual prefeito. Assim sendo, novas modificações toponímicas poderão ocorrer em Nilópolis evidenciando não necessariamente a importância dos homenageados, mas sim a força política do homenageador.

\section{CONSIDERAÇÕES FINAIS}

A discussão estabelecidaneste artigo suscita um debate referente ao público e ao privado na esfera nilopolitana, contudo, a prática desses grupos políticos cria um modelo gerencial no qual o privado se sobrepõe ao público, as individualidades se impõem sobre as políticas públicas mais amplas. A democracia representativa, que a priori sugere a ampliação das representativas nos debates públicos em razão da possibilidade de todos terem o mesmo direito em eleger representantes, é violentamente apropriada por grupos específicos, os quais elegem seus representantes quando ocupam a máquina pública, imprimindo um poder que reafirma suas identidades políticas.

Uma das manifestações da apropriação do espaço público para fins privados diz respeito à capacidade legítima de nomear os equipamentos e logradouros de uma cidade. $\mathrm{O}$ poder de nomear, por sua vez, está ancorado numa legitimação daquele que sugere a homenagem e/ou daquele que a recebe. A prática política atual no contexto nilopolitano demonstra que "o território, nessa perspectiva, é um espaço onde se projetou um trabalho, seja energia e informação, e que, por consequência, revela relações marcadas pelo poder (RAFFESTIN, 1993, p. 143). Como esse poder é passageiro, alguns espaços públicos nilopolitanos ficam à mercê de transformações toponímicas impostas por tais agentes públicos. A fim de criar um espaço de fato identitário entre os munícipes é preciso que esses espaços homenageiem personalidades desvinculadas da política partidária atual, ícones formadores da história municipal desconexos com os políticos "profissionais" do momento, entretanto, em Nilópolis percebemos o processo oposto.

Nomear espaços públicos sugere uma determinada imposição territorial sobre esses espaços e essa imposição, por sua vez, compromete a plenitude do caráter público desses locais por conta de sua apropriação particular. Desse modo, os agentes públicos privatizam simbolicamente tais espaços por meio do seu poder de nomear e as forças políticas 
vencedoras do momento utilizam a mesma estratégia para renomear, assim, nesse contexto, "aos vencedores, as toponímias".

\section{REFERÊNCIAS}

ABREU, M. A. Evolução Urbana do Rio de Janeiro. 4 ed. Rio de Janeiro: IPP, 2010.

ARENDT, H. Sobre a Violência. Rio de Janeiro: Civilização Brasileira, 2016.

ALVES, J. C. S. Dos Barões ao Extermínio: Uma História da Violência na Baixada

Fluminense. Duque da Caxias, RJ: APPH-CLIO, 2003.

AZEVEDO, J. B.de; MONTEIRO, Marcus. Inventário dos Bens Culturais de Nilópolis. Nilópolis (RJ): Prefeitura de Nilópolis, 2012.

CEPERJ (2014). Mapa da Região Metropolitana do Rio de Janeiro. Disponível em http://www.ceperj.rj.gov.br/ceep/info_territorios/RMRJ2013.pdf

CLAVAL, P. A geografia cultural. Florianópolis: EdUFSC, 2001.

FOUCAULT, M. Microfísica do poder. Organização e tradução de Roberto Machado. Rio de Janeiro: Paz e Terra, 2016.

GOMES, P. C. C. A condição urbana: ensaios de geopolítica da cidade. Rio de Janeiro: Bertrand Brasil, 2002.

IBGE. Censo Demográfico. 1940; 1950; 1960; 1970; 1980; 1991; 2000 e 2010

Diretoria de Pesquisas, Coordenação de Contas Nacionais. Produto Interno Bruto dos Municípios 2007 (disponível em www.ibge.gov.br).

JUPIARA, A.; OTAVIO, C. Os Porões da Contravenção: jogo do bicho e ditadura militar: a história da aliança que profissionalizou o crime organizado. Rio de Janeiro: Record,2016.

LAGO, L. C.do. Desigualdades e Segregação na Metrópole: o Rio de Janeiro em Tempo de Crise. Rio de Janeiro: Revan, 2000.

MELLO, J. B. F.A criatividade toponímica do povo carioca. II Colóquio Nacional do ANNER, Paraná, Curitiba, 2007.

NOGUEIRA, M. A. M. Memorial Nilopolitano. Nilópolis: Prefeitura de Nilópolis, 2009.

PERES, G. Nilópolis, Seu Povo, Sua História. Diário Fluminense, Nilópolis, Nov-2010/mar2011. 
RAFFESTIN, C. Por uma Geografia do Poder. São Paulo: Ática, 1993.

RIBEIRO, M.A.; O’ NEILL, M. M. V. C. Considerações sobre a dinâmica populacional fluminense: contrastes entre a metrópole e o interior. In: MARAFON, G. J RIBEIRO, M. A. (orgs). Revisitando o território fluminense IV. Rio de Janeiro: Gramma, 2012.

SIMÕES, M. R. A Cidade Estilhaçada: Reestruturação Econômica e Emancipações Municipais na Baixada Fluminense. 1 ed. Mesquita-RJ: Entorno, 2008. 